\title{
Complex molecule formation around massive young stellar objects
}

\section{Citation}

Öberg, Karin I., Edith C. Fayolle, John B. Reiter, and Claudia Cyganowski. 2014. “Complex Molecule Formation Around Massive Young Stellar Objects." Faraday Discussions 168 (February 6): 81. doi:10.1039/c3fd00146f.

\section{Published Version}

10.1039/C3FD00146F

\section{Permanent link}

http://nrs.harvard.edu/urn-3:HUL.InstRepos:25582892

\section{Terms of Use}

This article was downloaded from Harvard University's DASH repository, and is made available under the terms and conditions applicable to Open Access Policy Articles, as set forth at http:// nrs.harvard.edu/urn-3:HUL.InstRepos:dash.current.terms-of-use\#OAP

\section{Share Your Story}

The Harvard community has made this article openly available.

Please share how this access benefits you. Submit a story.

\section{Accessibility}




\title{
Complex molecule formation around mas- sive young stellar objects
}

\author{
Karin I. Öberg, ${ }^{a}$ Edith C. Fayolle, ${ }^{a}$ John B. Reiter, ${ }^{b}$ and Clau- \\ dia Cyganowski ${ }^{c}$
}

\author{
Received Xth XXXXXXXXXX 20XX, Accepted Xth XXXXXXXXX 20XX \\ First published on the web Xth $X X X X X X X X X X 200 X$
}

DOI: 10.1039/c000000x

Interstellar complex organic molecules were first identified in the hot inner regions of massive young stellar objects (MYSOs), but have more recently been found in many colder sources, indicating that complex molecules can form at a range of temperatures. Individually these observations provide limited constraints, however, on how complex molecules form, and whether the same formation pathways dominate in cold, warm and hot environments. To address these questions, we use spatially resolved observations from the Submillimeter Array of three MYSOs together with mostly unresolved literature data to explore how molecular ratios depend on environmental parameters, especially temperature. Toward the three MYSOs, we find multiple complex organic emission peaks characterized by different molecular compositions and temperatures. In particular, $\mathrm{CH}_{3} \mathrm{CCH}$ and $\mathrm{CH}_{3} \mathrm{CN}$ seem to always trace a luke-warm $(\mathrm{T} \sim 60 \mathrm{~K})$ and a hot $(\mathrm{T}>100 \mathrm{~K})$ complex chemistry, respectively. These spatial trends are consistent with abundance-temperature correlations of four representative complex organics $-\mathrm{CH}_{3} \mathrm{CCH}, \mathrm{CH}_{3} \mathrm{CN}, \mathrm{CH}_{3} \mathrm{OCH}_{3}$ and $\mathrm{CH}_{3} \mathrm{CHO}-$ in a large sample of complex molecule hosts mined from the literature. Together these results indicate a general chemical evolution with temperature, i.e. that new complex molecule formation pathways are activated as a MYSO heats up. This is qualitatively consistent with model predictions. Furthermore, these results suggest that ratios of complex molecules may be developed into a powerful probe of the evolutionary stage of a MYSO, as well as provide information about its formation history.

\section{Introduction}

Complex Organic Molecules (COMs)* were first detected towards massive young stellar objects, in so-called hot cores. These hot cores are characterized by intense and crowded millimeter and sub-millimeter spectra, where most of the lines are attributed to COMs, and gas temperatures exceed $100 \mathrm{~K}^{1,2}$. In the past couple

${ }^{a}$ Harvard-Smithsonian Center for Astrophysics, 60 Garden St, MS 16, Cambridge, MA, 02138, U.S.A.; E-mail: koberg@cfa.harvard.edu

${ }^{b}$ University of Virginia, Charlottesville, VA, U.S.A.

${ }^{c}$ St. Andrews University, U.K.

* For the purpose of this paper, COMs are defined as hydrogen-rich organics with three or more heavy elements 
of decades COMs have also been detected toward low-mass protostars ${ }^{3-5}$, often referred to as hot corinos, protostellar envelopes ${ }^{6}$, outflows ${ }^{7}$, and, most recently, two pre-stellar cores ${ }^{8-10}$. Together these observations suggest that COM chemistry can take place over a much larger range of temperatures than previously assumed, and that if properly understood, specific COM compositions and ratios could be used as precise probes of different aspects of low- and high-mass star formation.

This existence of low-temperature formation pathways of COMs does not exclude, however, that additional formation pathways of COMs are activated as the source temperature is increased. Indeed, there is evidence for significantly different COM compositions both between different kinds of sources (Fig. 1) ${ }^{11}$ and across a single massive young stellar object (MYSO) where the COM abundance profiles were resolved across a range of temperatures ${ }^{12}$. In this paper we aim at combining spatially resolved observations of a small sample of MYSOs with statistics from single-point observations of a diverse sample of COM hosts to explore whether there are clear trends in the COM chemistry between different classes of sources, and how such trends relate to source characteristics, especially temperatures.

The focus on source temperature as a potential COM chemistry regulator is motivated by the currently most popular astrochemical scenario, where COM formation takes place in three distinct stages or generations as material heats up during star formation ${ }^{2,13,14}$. The precursors of COMs, or the zeroth generation, form in cold molecular clouds, where low temperatures $(\sim 10 \mathrm{~K})$ and moderately high densities $\left(\sim 10^{5} \mathrm{~cm}^{-3}\right)$ result in efficient freeze-out of all elements and molecules heavier than $\mathrm{H}$ and $\mathrm{He}$ onto interstellar dust grains. While $\mathrm{H}$ atoms do not form permanent ice layers, they can still reside long enough on grain and ice surfaces to be an important reaction partner at low temperatures. At $10 \mathrm{~K}, \mathrm{H}$ is also orders of magnitude more mobile than heavier elements and molecules, such as $\mathrm{C}$ and $\mathrm{CO}$, and this stage is therefore characterized by hydrogenation-reactions on grain surfaces to form e.g. $\mathrm{CH}_{3} \mathrm{OH}$ from $\mathrm{CO}$. Some heavier atom additions must also occur to form e.g. $\mathrm{CO}_{2}$, and possibly $\mathrm{HNCO}$ and other small COMs ${ }^{11,15,16}$. In the gas-phase this stage is characterized by ion-neutral reactions, which may be responsible for some COMs, especially hydrocarbons.

$\mathrm{COM}$ ice formation is expected to become efficient in the following phase when the cloud core collapses to form a protostar, resulting in heating due to dissipation of gravitational energy. At these elevated temperatures $(>30 \mathrm{~K})$ diffusion of larger molecules and radicals in the ice is possible. Radicals are continuously produced in the ice through dissociative absorption of high-energy photons and electrons. When mobile, these radicals can combine to form complex molecules, so called first generation COMs ${ }^{2}$. The final stage of COM chemistry happens when the gas temperature exceeds $100 \mathrm{~K}$, the hot core stage, releasing all the ice into the gas phase and also enabling further gas-phase processing into even more complex species (second generation $\mathrm{COMs}^{2,17}$ ). This model has been very successful in explaining the kinds of molecules that appear in hot cores and can also explain the different excitation temperatures extracted for different COMs in these sources ${ }^{14}$.

Comprehensive tests of this formation scenario, and therefore our basic understanding of COM formation, have been scarce, however. In this study we

2 | Faraday Discuss., [year], [vol], 1-19

This journal is $\odot$ The Royal Society of Chemistry [year] 


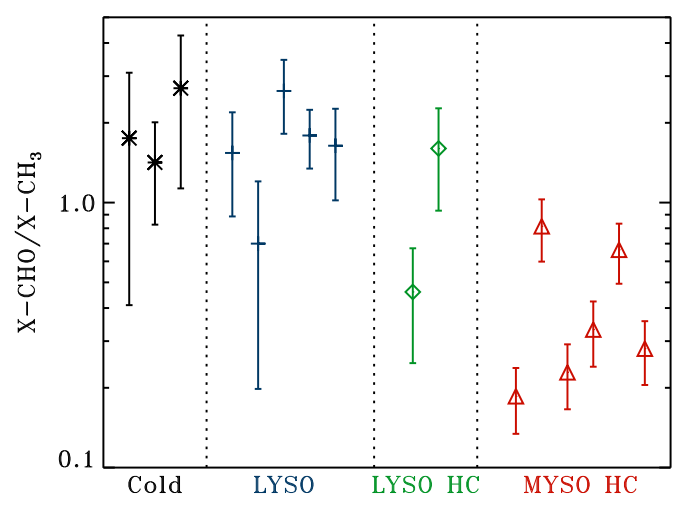

Fig. 1 The ratio of $\left(\mathrm{CH}_{3} \mathrm{CHO}+\mathrm{HCOOCH}_{3}\right) /\left(\mathrm{CH}_{3} \mathrm{OCH}_{3}+\mathrm{CH}_{3} \mathrm{CH}_{2} \mathrm{OH}\right)$ abundances toward cold sources (pre-stellar cores and an outflow), low-mass protostellar envelopes, low-mass hot cores, and traditional high-mass hot cores ${ }^{11}$. Based on laboratory experiments the relative abundance of $\mathrm{CHO}$-bearing molecules should trace the relative importance of cold (CO-ice rich) and warm ice COM chemistry ${ }^{18}$. Literature column densities without uncertainties were assigned a $20 \%$ uncertainty.

combine submillimeter observations of three MYSOs with statistics drawn from a large number of previous observational studies to explore how the COM chemistry depends on temperature across and between sources. The observations are briefly described in $\S 2$. In $\S 3$ we present emission maps of key COM lines toward the three MYSOs and present new strategies to quantify the COM distributions. The extracted COM column density ratios are then used together with literature values to evaluate which, if any, aspects of the COM chemistry are regulated by source temperature. The implications of the results are discussed in $\S 4$, followed by a brief summary of the results of this paper and open questions that remain on COM formation.

\section{Observations and Source Characteristics}

The three MYSOs, W3 IRS5, NGC 7538 IRS 9 and NGC 7538 IRS 1 (Table 1) are all nearby $(\mathrm{d}<3 \mathrm{kpc})$ and have comparable luminosities and virial envelope mass estimates. All sources are associated with multiple molecular outflows, and thus multiple YSOs within larger structure. NGC7538 IRS9 and NGC7538 IRS1 are located in Perseus, and NGC7538 IRS1 is known to house a bright hot core ${ }^{19}$ and is situated in the middle of a cluster of continuum peaks and molecular outflows. W3 IRS5 is associated with at least five young stellar objects, two of which are massive ${ }^{20-24}$, and is known to present strong S-bearing molecular lines ${ }^{25}$. In summary all three sources are known to have complicated structures with many different potential origins of complex molecular emission. This is a nuisance when interpreting spatially unresolved observations, but in the age of interferometry this increases the potential value of each MYSO data set: resolving several different environments with a single observation enables an efficient exploration of COM chemistry environmental dependencies.

All three MYSOs are known to host complex organics (Fayolle et al. ApJ, 
subm.) ${ }^{12}$ and to present a different molecular composition on large and small scales. In this study, we focus on resolving the chemical differentiation on the individual core scale using observations from the Submillimeter Array ${ }^{\dagger}$ (SMA). W3 IRS5, NGC 7538 IRS 9 and NGC 7538 IRS 1 were observed on July 29th and August 15th (extended configuration) and October 15th (compact configuration) 2011 in good to excellent weather: $\tau_{225 \mathrm{GHz}}$ was 0.09 on the 29 th of July, 0.1 on the 15th of August, and 0.07 on the 15th of October 2011.

The combined range of baselines was 16-226 m. The SMA correlator was set up to obtain a spectral resolution of $\sim 1 \mathrm{~km} \mathrm{~s}^{-1}$ using 128 channels for each of the 46 chunks covering $227-231 \mathrm{GHz}$ in the lower sideband and $239-243 \mathrm{GHz}$ in the upper sideband. Absolute flux calibration was done with Callisto. The quasars 1924-292 and 3c84 were used as bandpass calibrators for the compact observations, and $3 c 454.3$ and $3 c 279$ were used to calibrate the 29th of July and 15th of July observations respectively. The quasars $0014+612$ and $0102+584$ were used as gain calibrators for NGC7538 IRS9 and IRS1, and 0244+624, 0359+509 and 0102+584 were used for W3 IRS5.

Routine calibration tasks were performed using the CASA software package $^{26}$, including phase and amplitude self-calibration. The continuum was subtracted separately for the upper and lower sideband for each observational data set in CASA, using line-free channels. The continuum-subtracted compact and extended data were combined for each source for imaging and CLEANing in CASA using robust weighting, which resulted in synthesized beam sizes of 2.0 " $\times 1.7$ " for NGC 7538 IRS 9 and W3 IRS5, and 1.5" $\times 1.7$ " for NGC7538 IRS 1. The primary beam of the SMA at these wavelengths is $\sim 50 "$ ". Considering the baseline coverage, all emission at scales larger than 18 " is completely filtered out, and angular structures smaller than 7" are required to filter out less than $50 \%$ of the emission ${ }^{27}$. These observations are thus not sensitive to large-scale envelope COM chemistry as explored in our previous papers using the IRAM $30 \mathrm{~m}$ (Fayolle et al. ApJ, subm.) $^{12}$.

Table 1 Source characteristics ${ }^{28}$.

\begin{tabular}{lccccc}
\hline \hline Source & RA & Dec & $\mathrm{d}$ & $\mathrm{L}$ & $\mathrm{M}_{\mathrm{V}}$ \\
\hline \hline & & & $\mathrm{kpc}$ & $10^{4} \mathrm{~L}_{\odot}$ & $10^{4} \mathrm{M}_{\odot}$ \\
\hline W3 IRS5 & 022153.1 & +615220 & 2.0 & 17 & 2.0 \\
NGC7538 IRS9 & 231152.8 & +611059 & 2.7 & 3.5 & 1.1 \\
NGC7538 IRS1 & 231136.7 & +611150.8 & 2.7 & 13 & 1.0 \\
\hline
\end{tabular}

\section{Results}

\subsection{Molecular image analysis}

Figure 2 shows the continuum and line images toward W3 IRS5, NGC 7538 IRS 9 and NGC 7538 IRS 1. Each source displays multiple continuum peaks as

$\dagger$ The Submillimeter Array is a joint project between the Smithsonian Astrophysical Observatory and the Academia Sinica Institute of Astronomy and Astrophysics. It is funded by the Smithsonian Institute and the Academia Sinica.

4| Faraday Discuss., [year], [vol], 1-19

This journal is $\odot$ The Royal Society of Chemistry [year] 
expected from previous studies. These peaks are marked and referred to throughout the text when discussing the chemical differentiation within these sources. The molecular images display the spectrally integrated (across the line FWHM), spatially resolved emission profiles of 7 organic emission lines, including lines from the $\mathrm{COMs} \mathrm{HNCO}, \mathrm{CH}_{3} \mathrm{CN}$, and $\mathrm{CH}_{3} \mathrm{CCH}$ detected in all sources. Multiple lines were detected for each molecule. The lines in Fig. 2 were selected to have similar upper level energies (Table 2), which minimizes differences in emission profiles due to differences in excitation characteristics. This allows us to use these line emission patterns to visualize the spatial extents of different molecules, i.e. different emission profiles should be mainly driven by differences in molecular abundance profiles.

In all three sources there is a clear difference in emission profiles between different molecular lines. Some line emission, e.g. $\mathrm{HNCO}$ and $\mathrm{CH}_{3} \mathrm{CN}$, mostly originates in a single unresolved component, which can be associated with a continuum peak (the hot core, in the case of NGC 7538 IRS1). Other lines, especially those belonging to $\mathrm{CH}_{3} \mathrm{CCH}$, are more diffusively distributed and the $\mathrm{CH}_{3} \mathrm{CCH}$ line emission peaks are not associated with any detected continuum. Three molecules, $\mathrm{CH}_{3} \mathrm{OH}, \mathrm{H}_{2} \mathrm{CS}$ and $\mathrm{HC}_{3} \mathrm{~N}$, display different kinds of profiles across the small sample: in NGC 7538 IRS1 most of their emission can be attributed to the unresolved hot core, while the emission is clearly resolved in the other two sources. The differences in the spatial distributions of these different groups of COMs are suggestive of multiple COM formation pathways, which may be associated with the theoretically predicted low-temperature gas and ice chemistry, luke-warm ice chemistry, and ice evaporation in hot cores.

Table 2 Molecular line data for imaged lines in Fig $2^{\mathrm{a}}$.

\begin{tabular}{lcccc}
\hline \hline Species & Frequency [GHz] & $\log \left(\mathrm{A}_{i j}\right)$ & $\mathrm{E}_{u}[\mathrm{~K}]$ & $\mathrm{d}_{u}{ }^{\mathrm{b}}$ \\
\hline $\mathrm{HNCO}$ & 241.774 & -3.71 & 69 & 23 \\
$\mathrm{CH}_{3} \mathrm{OCH} \mathrm{H}_{3}$ & 241.946 & -3.78 & 81 & 378 \\
$\mathrm{CH}_{3} \mathrm{OH}$ & 241.833 & -4.41 & 84 & 22 \\
$\mathrm{CH}_{3} \mathrm{CN}$ & 239.133 & -2.93 & 87 & 54 \\
$\mathrm{H}_{2} \mathrm{CS}$ & 240.267 & -3.69 & 46 & 15 \\
$\mathrm{HC}_{3} \mathrm{~N}$ & 227.419 & -3.03 & 141 & 51 \\
$\mathrm{CH}_{3} \mathrm{CCH}$ & 239.252 & -4.84 & 86 & 58 \\
\hline
\end{tabular}

${ }^{\mathrm{a}}$ From $\mathrm{CDMS}$ and JPL spectral databases ${ }^{29,30 .}{ }^{\mathrm{b}}$ Degeneracy in the upper level.

Despite our careful selection of lines in Fig. 2, we cannot completely neglect the fact that emission from individual lines always depends on a combination of molecular abundance and excitation. To establish a firm relationship between COM line emission and abundance distributions thus requires the imaging of multiple lines. This is especially true in cases where the continuum and line emission distributions are complex, such as W3 IRS5. Even in these moderately rich sources, images of all detected lines $(50+)$ would be difficult to absorb, and therefore not very informative. Instead Figure 3 shows, in a single figure, the line emission peaks of all clearly detected COM and S-molecule lines toward W3 IRS5 together with the continuum. The line emission peaks were determined by fitting 2D Gaussians in the image plane, integrated over the FWHM of each line, 


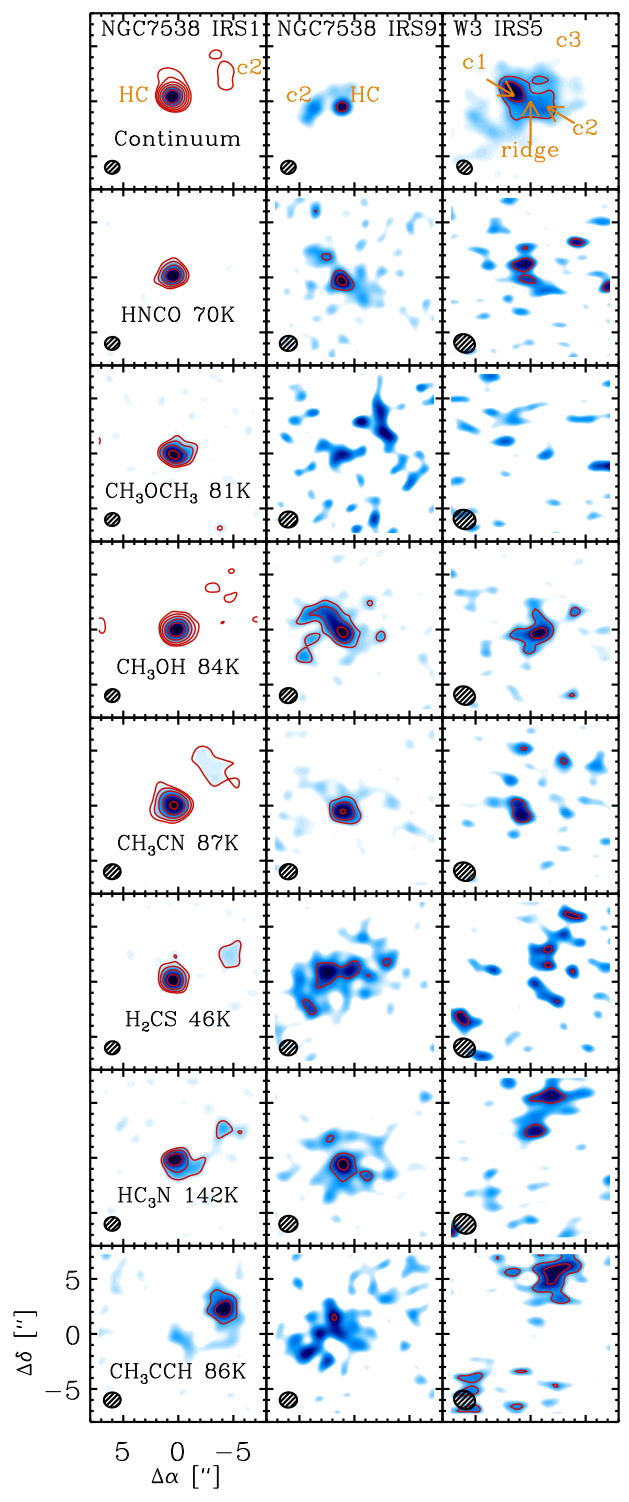

Fig. 2 Continuum and molecular line emission maps. The continuum maps in the top panels show the locations of the brightest continuum emission and the $\mathrm{CH}_{3} \mathrm{CCH}$ core in the $\mathrm{NW}$ of W3 IRS 5. The panel labels indicate species and upper level energy in $\mathrm{K}$ (other line characteristics are listed in Table 2). The red contours mark $[0.05,0.1,0.2,0.4,0.8,1.6] \mathrm{Jy} / \mathrm{beam}$ in the continuum panels, and $[0.5,1,2,4,8] \mathrm{Jy} \mathrm{km} / \mathrm{s} \mathrm{beam}^{-1}$ in the molecular line panels. The synthesized beam is displayed in the bottom left corner of each panel. The RA and Dec offsets are with respect to the positions listed in Table 1. 
in CASA. The uncertainties of these fits (typically $\sim 0.5$ ") are also shown.

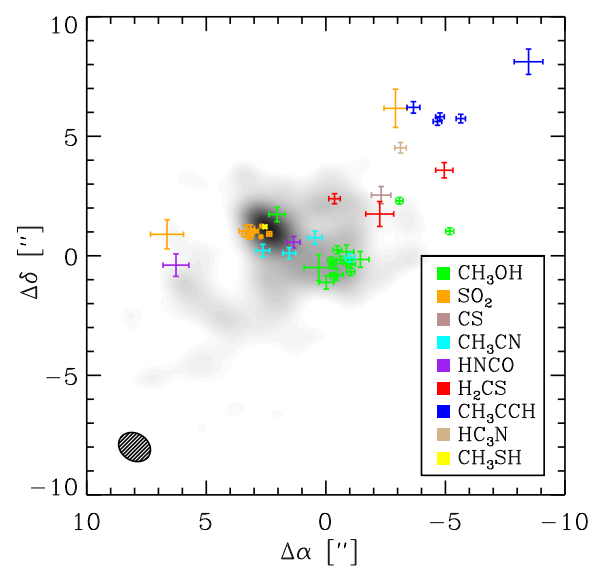

Fig. 3 The continuum emission $(1 \mathrm{~mm})$ toward W3 IRS5 (gray scale) and the spatially resolved line emission peaks of all detected COMs and S-bearing molecules toward this source. The error bars mark the uncertainties in the peak positions based on Gaussian fits. Most lines are heavily clustered dependent on species. A few exceptions are $\mathrm{CH}_{3} \mathrm{CN}$, which is spread out across the ridge connecting the $\mathrm{SO}_{2}$ and $\mathrm{CH}_{3} \mathrm{OH}$ cores, and $\mathrm{H}_{2} \mathrm{CS}$. The two continuum peaks seem to be chemically defined by $\mathrm{SO}_{2}$ and $\mathrm{CH}_{3} \mathrm{OH}$ line emission.

Most $\mathrm{SO}_{2}$ lines are clustered toward the 'c1' continuum peak from Fig. 2, while $\mathrm{CH}_{3} \mathrm{OH}$ line emission seems to define the second continuum peak ' $\mathrm{c} 2$ '. $\mathrm{CH}_{3} \mathrm{CN}$ and $\mathrm{HNCO}$ are not obviously associated with either peak, but rather reside in a ridge connecting the two clumps. $\mathrm{CH}_{3} \mathrm{CCH}$ lines form another cluster in the northwest, and the space in between this cluster and the continuum peaks is associated with $\mathrm{H}_{2} \mathrm{CS}, \mathrm{HC}_{3} \mathrm{~N}$ and some $\mathrm{CH}_{3} \mathrm{OH}$. There is also some diffuse emission of $\mathrm{HNCO}$ and $\mathrm{SO}_{2}$ to the east. These molecular line clusters partly coincide with the chemical regions identified by Wang et al. (2013) ${ }^{24}$, i.e. both studies found ' 1 ' ' and 'c2' to be defined by $\mathrm{SO}_{2}$ and $\mathrm{HNCO}$, and by $\mathrm{CH}_{3} \mathrm{OH}$, respectively. Wang et al. (2013) classified the 'c1' peak as a pole-on outflow and the 'c2' peak as a budding hot core. Both studies also found $\mathrm{CS}$ and $\mathrm{H}_{2} \mathrm{CS}$ in the NW region, but the discovery of $\mathrm{CH}_{3} \mathrm{CCH}$ is new, and so is the realization that the ridge connecting ' $\mathrm{c} 1$ ' and 'c2' seems to be chemically distinct, and the source of N-bearing COMs.

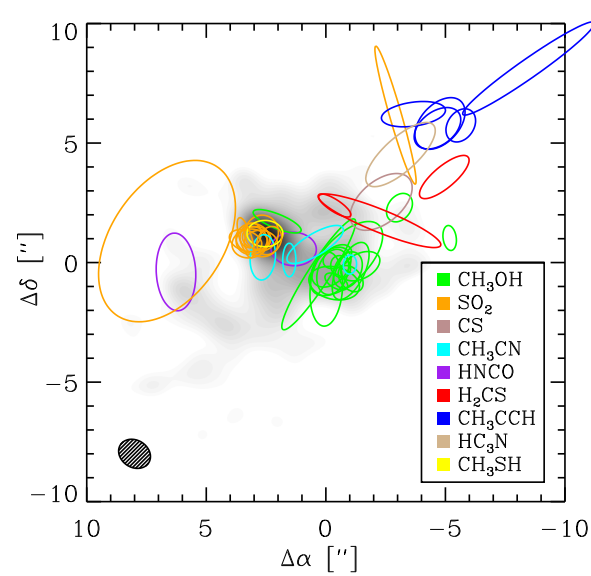

Fig. 4 The continuum emission $(1 \mathrm{~mm})$ toward W3 IRS5 (gray scale) and the spatially resolved line emission peaks of all detected COMs and S-bearing molecules toward this source. The ellipses mark the best-fit 2D Gaussians $(\times 0.5$ for visibility). It is clear that for each species the best fit ellipses vary in size, but some of this is due to differences in emission line strength rather than actual emission region differences. The emission regions centered on the $\mathrm{c} 1$ core do seem significantly more compact compared to all other emission, however.

The sizes of the different line emission regions are displayed in Fig. 4 based 
on the Gaussian fitting parameters (major and minor axes, center, and position angle). The line emission peaking on the ' $\mathrm{c} 1$ ' core is compact. The other line emission centers display a range of emission sizes. Large ratios between the major and minor axes are mainly associated with very weak lines, suggesting that the 'true' line emission profiles are typically close to circular or unresolved.

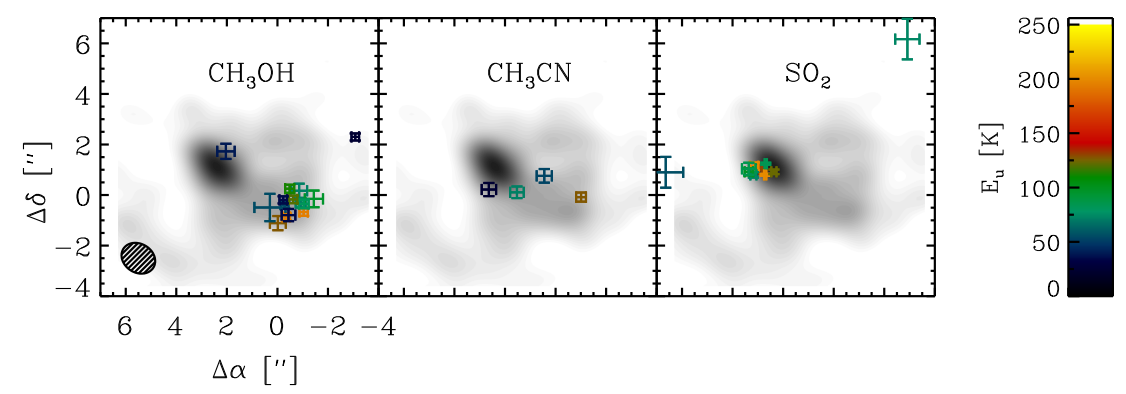

Fig. 5 The continuum emission $(1 \mathrm{~mm})$ toward the central cores in W3 IRS5 (gray scale) and the spatially resolved line emission peaks of $\mathrm{CH}_{3} \mathrm{OH}, \mathrm{CH}_{3} \mathrm{CN}$ and $\mathrm{SO}_{2}$ lines, color-coded by their upper energy levels. In each line there seems to be a temperature gradient. $\mathrm{CH}_{3} \mathrm{OH}$ and $\mathrm{SO}_{2}$ high temperature lines seem to trace the very center of their respective cores, while the $\mathrm{CH}_{3} \mathrm{CN}$ line emission centers suggest an increasing temperature from east to west across the ridge.

Based on the previous two figures, $\mathrm{SO}_{2}, \mathrm{CH}_{3} \mathrm{OH}$ and $\mathrm{CH}_{3} \mathrm{CN}$ have multiple emission centers, which may be indicative of different lines tracing different excitation conditions. To explore this, Figure 5 shows the distribution of emission centers for these lines as a function of upper energy levels. In all cases, there are line-energy dependent differences in the emission centers. For $\mathrm{CH}_{3} \mathrm{OH}$, the line emission that peaks away from 'c2' comes from low energy lines. Furthermore, within the 'c2' line emission cluster the higher energy lines $\left(E_{\mathrm{up}}>100 \mathrm{~K}\right)$ peak closer to the western side of ' $c 2$ '. There are only 4 detected $\mathrm{CH}_{3} \mathrm{CN}$ lines and they are distributed along the ridge, with the lowest level line in the $\mathrm{NE}$ and the highest level line in the $\mathrm{SW}$, indicative of a temperature gradient in the same direction as seen for $\mathrm{CH}_{3} \mathrm{OH}$. Finally, the $\mathrm{SO}_{2}$ line emission distribution presents a similar trend to $\mathrm{CH}_{3} \mathrm{OH}$, with lower lying lines more offset from the ' $\mathrm{c} 1$ ' core.

\subsection{Excitation temperatures and column densities}

The line emission maps presented in Fig. 2 could theoretically be converted into column density maps, using the emission from all detected lines of each species at each spatial resolution element. If local thermal equilibrium (LTE) in each pixel and optically thin lines can be assumed this would be rather straightforward using e.g. rotational diagrams ${ }^{31}$. Such an approach should be very fruitful with ALMA, whose orders of magnitude increase in sensitivity and densely populated antenna arrays will result in very high SNR and image fidelity.

The current observations suffer from too low SNR to allow for this kind of detailed analysis, however. Instead, Fig. 6 shows the spectra extracted from all 8 continuum and molecular emission peak centers marked in Fig. 2 using a 2"-diameter circular mask. As expected from the image analysis in the previ-

8 | Faraday Discuss., [year], [vol], 1-19

This journal is @ The Royal Society of Chemistry [year] 
ous section, the spectra appear very different toward the different sources, and toward the different peaks within each source. In particular, the maximum intensity of the $\mathrm{CH}_{3} \mathrm{OH}$ 5-4 ladder is orders of magnitude lower toward W3 IRS5 and NGC 7538 IRS9 compared to NGC 7538 IRS1. $\mathrm{SO}_{2}$ is also relatively more important in the latter two sources. There are also some trends across the sample: strong $\mathrm{CH}_{3} \mathrm{OH}$ lines appear to coincide with strong $\mathrm{CH}_{3} \mathrm{CN}$ lines, while strong $\mathrm{CH}_{3} \mathrm{CCH}$ lines are associated with no or very weak emission of any other molecule, including $\mathrm{CH}_{3} \mathrm{OH}$.

We use these spectra to extract excitation temperatures at each position using $\mathrm{CH}_{3} \mathrm{OH}, \mathrm{CH}_{3} \mathrm{CCH}$ or $\mathrm{CH}_{3} \mathrm{CN}$ lines, dependent on the availability of lines, and the rotational diagram method. We could not identify a sufficient number of lines of any of these species toward the 'c1' (S-core) or 'c2' core in W3 IRS5 or the 'c2' core in NGC7538 IRS9, and exclude these positions from further analysis. The derived temperatures in the remaining cores range between 60 and $200 \mathrm{~K}$ and are shown in Table 3. The rotational temperature toward the W3 IRS5 ridge is, however, highly uncertain because of the small number and low SNR of the $\mathrm{CH}_{3} \mathrm{CN}$ lines

The listed excitation temperatures are used to determine column density (limits) of $\mathrm{CH}_{3} \mathrm{OH}$ and the four $\mathrm{COMs}, \mathrm{CH}_{3} \mathrm{CN}, \mathrm{CH}_{3} \mathrm{OCH}_{3}, \mathrm{CH}_{3} \mathrm{CCH}$ and $\mathrm{CH}_{3} \mathrm{CHO}$, which are expected to be products of a diverse set of complex formation pathways $^{13}$. For each molecule we use between one and five detected lines to derive a column density, or the spectral rms to determine a $3 \sigma$ upper limit. This approach results in substantial uncertainties, especially since it is a priori not clear that all species in the same line of sight have the same excitation temperature, but provides a first quantitative constraint on how the complex chemistry varies at these scales.

To check the accuracy of the derived column densities we compared with previous studies when possible. Two of the sources, NGC 7538 IRS1 HC and W3 IRS5 c2, have been observed previously by others ${ }^{24,32}$. In the case of NGC 7538 IRS1 HC, the derived $\mathrm{CH}_{3} \mathrm{OH}, \mathrm{CH}_{3} \mathrm{CN}$ and $\mathrm{CH}_{3} \mathrm{OCH}_{3}$ columns are consistent with previous observations, while the $\mathrm{CH}_{3} \mathrm{CHO}$ and $\mathrm{CH}_{3} \mathrm{CCH}$ columns are at least an order of magnitude higher in our study. Previous studies were single dish however, and assumed a beam dilution factor commensurate with the expected $100 \mathrm{~K}$ hot core boundary for most molecules, except for designated cold molecules $\mathrm{CH}_{3} \mathrm{CCH}$ and $\mathrm{CH}_{3} \mathrm{CHO}$, which presented low excitation temperatures. The discrepancy is therefore readily resolved if $\mathrm{CH}_{3} \mathrm{CHO}$ and $\mathrm{CH}_{3} \mathrm{CCH}$ abundances are enhanced in the hot core compared to the envelope, even if most of the single-dish emission does indeed originate in the envelope, resulting in an average low excitation temperature. In the case of W3 IRS5, the derived $\mathrm{CH}_{3} \mathrm{OH}$ column densities are also consistent between our and previous observations.

The resulting $\mathrm{CH}_{3} \mathrm{OH}$ column densities span $10^{14}-10^{17} \mathrm{~cm}^{-2}$, with the higher column densities toward the warmer sources. $\mathrm{CH}_{3} \mathrm{CN}$ column densities vary over two orders of magnitude, and seem correlated with temperature as well. In contrast, the $\mathrm{CH}_{3} \mathrm{CCH}$ column densities are almost constant across this small sample. $\mathrm{CH}_{3} \mathrm{OCH}_{3}$ and $\mathrm{CH}_{3} \mathrm{CHO}$ are only detected toward the NGC7538 IRS1 hot core, but are known to exist on larger scales toward the other two MYSOs (Fayolle et al. ApJ subm.). 

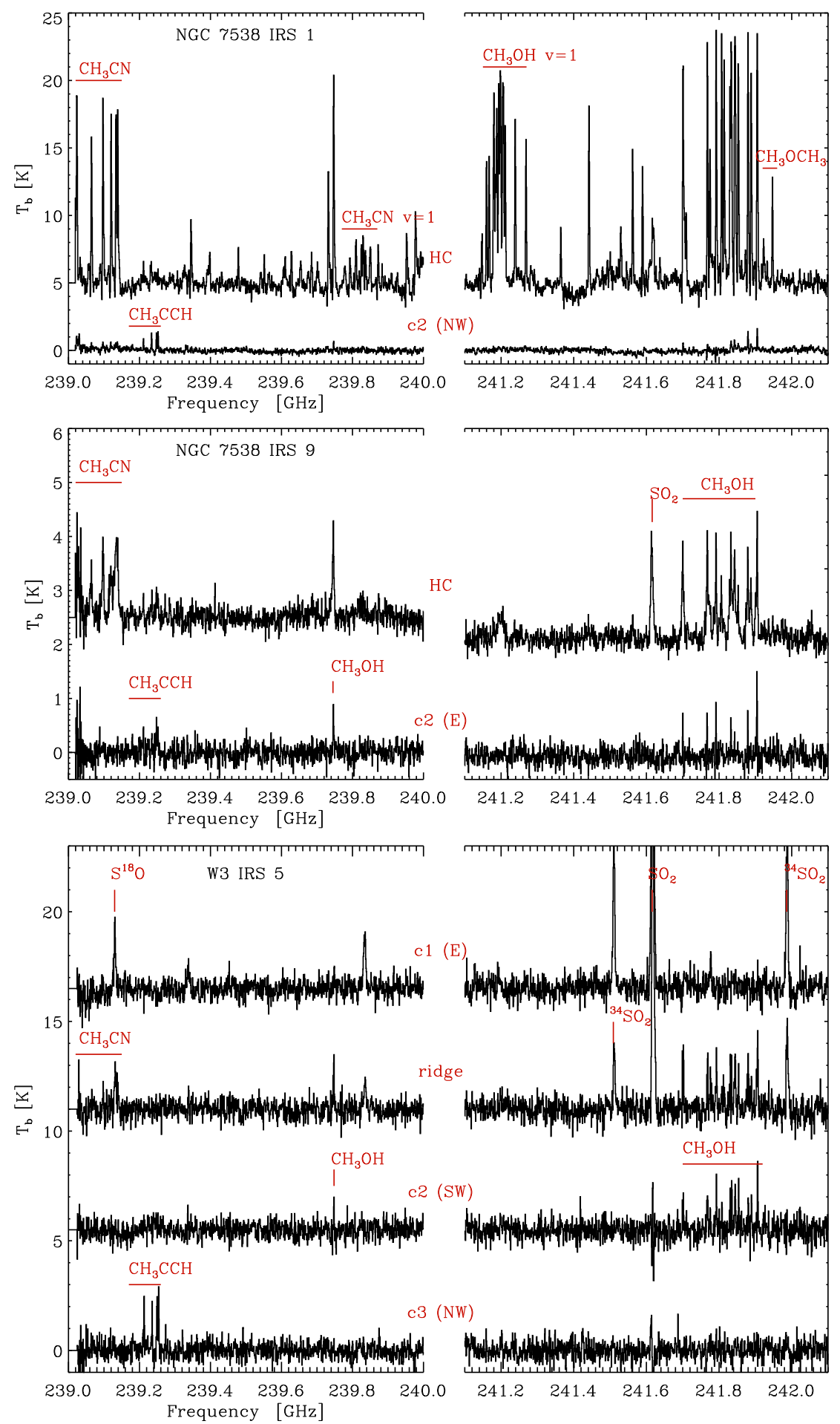

Fig. 6 Spectra extracted from the positions marked in Fig. 2, using 2" (diameter) circular masks. Key molecular ladders and lines are marked.

10 | Faraday Discuss., [year], [vol], 1-19

This journal is $\odot$ The Royal Society of Chemistry [year] 
Table 3 Excitation temperatures and COM column densities in MYSO cores.

\begin{tabular}{|c|c|c|c|c|c|c|c|}
\hline$\overline{\text { Core }}$ & $\mathrm{X}$ & $\begin{array}{c}\mathrm{T}_{\mathrm{rot}}(\mathrm{X}) \\
{[\mathrm{K}]} \\
\end{array}$ & $\begin{array}{l}\mathrm{N}_{\mathrm{CH}_{3} \mathrm{OH}} \\
{\left[\mathrm{cm}^{-2}\right]}\end{array}$ & $\begin{array}{l}\mathrm{N}_{\mathrm{CH}_{3} \mathrm{CN}} \\
{\left[\mathrm{cm}^{-2}\right]}\end{array}$ & $\begin{array}{c}\mathrm{N}_{\mathrm{CH}_{3}} \mathrm{OCH}_{3} \\
{\left[\mathrm{~cm}^{-2}\right]}\end{array}$ & $\begin{array}{c}\mathrm{N}_{\mathrm{CH}_{3} \mathrm{CCH}} \\
{\left[\mathrm{cm}^{-2}\right]} \\
\end{array}$ & $\begin{array}{c}\mathrm{N}_{\mathrm{CH}_{3} \mathrm{CHO}} \\
{\left[\mathrm{cm}^{-2}\right]} \\
\end{array}$ \\
\hline W3 IRS5 ridge & $\mathrm{CH}_{3} \mathrm{OH}$ & $\sim 130$ & $4[2] \times 10^{15}$ & $6[6] \times 10^{13}$ & $<6 \times 10^{14}$ & $<2 \times 10^{15}$ & $<3 \times 10^{14}$ \\
\hline W3 IRS5 c3 3 & $\mathrm{CH}_{3} \mathrm{CCH}$ & $78[30]$ & $3[4] \times 10^{14}$ & $<1 \times 10^{13}$ & $<3 \times 10^{14}$ & $4[2] \times 10^{15}$ & $<1 \times 10^{14}$ \\
\hline NGC 7538 IRS9 HC & $\mathrm{CH}_{3} \mathrm{OH}$ & $119[29]$ & $4.3[0.5] \times 10^{15}$ & $4[1] \times 10^{14}$ & $<2 \times 10^{14}$ & $4[1] \times 10^{15}$ & $<2 \times 10^{14}$ \\
\hline NGC 7538 IRS1 HC & $\mathrm{CH}_{3} \mathrm{CN}$ & $196[15]$ & $1.3[0.1] \times 10^{17}$ & $8.4[0.4] \times 10^{14}$ & $8[2] \times 10^{15}$ & $4[3] \times 10^{15}$ & $6[1] \times 10^{15}$ \\
\hline NGC 7538 IRS1 c2 & $\mathrm{CH}_{3} \mathrm{CCH}$ & $61[15]$ & $9[3] \times 10^{14}$ & $2[2] \times 10^{13}$ & $<2 \times 10^{14}$ & $2[1] \times 10^{15}$ & $<1 \times 10^{14}$ \\
\hline
\end{tabular}

\subsection{COM compositional dependencies}

To explore whether trends observed on small scales with respect to temperature are also present across samples of COM hosts, we have gathered COM data from the literature based on three criteria: (1) detection of $\mathrm{CH}_{3} \mathrm{OH}$, (2) determination of a $\mathrm{CH}_{3} \mathrm{OH}, \mathrm{CH}_{3} \mathrm{CN}$ or $\mathrm{CH}_{3} \mathrm{CCH}$ excitation temperature in the same line of sight, and (3) detections or limits on at least one of the four $\mathrm{COMS} \mathrm{CH}_{3} \mathrm{CN}$, $\mathrm{CH}_{3} \mathrm{OCH}_{3}, \mathrm{CH}_{3} \mathrm{CCH}$ and $\mathrm{CH}_{3} \mathrm{CHO}$. The resulting sample is listed in Table 4. It comprises 42 observations in 35 lines of sight (for seven targets there are measurements of both the extended and compact COM composition). The sample contains massive hot cores, MYSOs dominated by either cold or warm chemistry, low mass hot cores and envelopes, Galactic Center sources, IRDCs, an outflow and a cold pre-stellar core. It is thus representative of the full range of observed COM sources in space. The source diversity is also apparent when inspecting the reported excitation temperatures: 14 sources have excitation temperatures below $30 \mathrm{~K}$ (the traditional 0th generation regime), 10 sources have temperatures between 30 and $100 \mathrm{~K}$ (the temperature range when 1st generation COM chemistry should be active), and 18 sources have excitation temperatures above $100 \mathrm{~K}$, typical for hot cores. The observed $\mathrm{CH}_{3} \mathrm{OH}$ column densities span five orders of magnitude, between $10^{13}$ and $10^{18} \mathrm{~cm}^{-2}$. For all parameters we use the reported uncertainties when available and otherwise assume a typical $20 \%$ error.

Figure 7 shows that there is a strong trend between excitation temperature and $\mathrm{CH}_{3} \mathrm{OH}$ column density, consistent with the observed temperature dependence within our MYSO sample. Below $100 \mathrm{~K}$, the average $\log _{10}\left(\mathrm{~N}_{\mathrm{CH}_{3} \mathrm{OH}}\right)=14.9$ for the whole sample with a standard deviation of 0.6. At or above $100 \mathrm{~K}$, $\log _{10}\left(\mathrm{~N}_{\mathrm{CH}_{3} \mathrm{OH}}\right)=17.5$ with a standard deviation of 0.9 . Within these two subgroups there are no additional correlations visible. Furthermore, there seems to be a clear break in column densities right at $100 \mathrm{~K}$. This result may be somewhat biased, however, by the fact that most of the plotted values were acquired with single-dish telescopes, using a beam-dilution estimate. A common assumption is that if the excitation temperature is high, the emission area is small, e.g. a hot core, resulting in a potentially inflated column density estimate. We therefore also looked only at resolved observations, and find a similar trend as in the unresolved sample, except that NGC 7538 IRS9 HC seems to fall somewhere in between the two groupings, perhaps suggestive of a rare transitional object between an MYSO and a luminous hot core. In general, there thus seems to be a well-defined $\mathrm{CH}_{3} \mathrm{OH}$ evaporation front toward both low- and high-mass star forming regions.

Figure 8 shows the relationship between ratios of $\mathrm{CH}_{3} \mathrm{CN}, \mathrm{CH}_{3} \mathrm{OCH}_{3}, \mathrm{CH}_{3} \mathrm{CCH}$, $\mathrm{CH}_{3} \mathrm{CHO}$ and $\mathrm{CH}_{3} \mathrm{OH}$ and the observed excitation temperatures. In the sample 
Table 4 Previous observations of representative complex organic molecules

\begin{tabular}{|c|c|c|c|c|c|c|c|}
\hline ource & Type & $\begin{array}{l}\mathrm{T}_{\text {rot }} \\
{[\mathrm{K}]}\end{array}$ & $\begin{array}{l}\mathrm{N}_{\mathrm{CH}_{3} \mathrm{OH}} \\
{\left[\mathrm{cm}^{-2}\right]} \\
\end{array}$ & $\begin{array}{l}\mathrm{N}_{\mathrm{CH}_{3} \mathrm{CN}} \\
{\left[\mathrm{cm}^{-2}\right]}\end{array}$ & $\begin{array}{c}\mathrm{N}_{\mathrm{CH}_{3} \mathrm{OCH}_{3}} \\
{\left[\mathrm{~cm}^{-2}\right]}\end{array}$ & $\begin{array}{l}\mathrm{N}_{\mathrm{CH}_{3} \mathrm{CCH}} \\
{\left[\mathrm{cm}^{-2}\right]}\end{array}$ & $\begin{array}{l}\mathrm{N}_{\mathrm{CH}_{3} \mathrm{CHO}} \\
{\left[\mathrm{cm}^{-2}\right]}\end{array}$ \\
\hline IRAS20126+4104 33 & $\overline{\mathrm{HC}}$ & 300 & $1.1[0.1] \times 10^{17}$ & $1.3 \times 10^{15}$ & $1 \times 10^{16}$ & $\overline{-}$ & - \\
\hline IRAS20126+4104 33 & MYSO env & $14[1]$ & $2.2[0.9] \times 10^{15}$ & - & - & $3.5 \times 10^{14}$ & $<5 \times 10^{13}$ \\
\hline IRAS18089-1732 33 & $\mathrm{HC}$ & 300 & $2.0[0.2] \times 10^{17}$ & $>3.5 \times 10^{15}$ & $<1 \times 10^{17}$ & - & - \\
\hline IRAS18089-1732 33 & MYSO env & $15[2]$ & $2.4[1.4] \times 10^{15}$ & - & - & $9.4 \times 10^{14}$ & $<5 \times 10^{13}$ \\
\hline $\mathrm{G} 31.41+0.3133$ & $\mathrm{HC}$ & 200 & $1.0[0.2] \times 10^{18}$ & $>2.0 \times 10^{16}$ & $5 \times 10^{17}$ & - & . \\
\hline $\mathrm{G} 31.41+0.3133$ & MYSO env & 14[2] & $1.2[1.4] \times 10^{16}$ & - & - & $1.4 \times 10^{15}$ & $5 \times 10^{14}$ \\
\hline AFGL 259132 & $\mathrm{HC}$ & $147[11]$ & $4.7 \times 10^{16}$ & $<3.5 \times 10^{15}$ & $<7.7 \times 10^{15}$ & $7.9 \times 10^{14}$ & $3.1 \times 10^{12}$ \\
\hline G24.78 32 & $\mathrm{HC}$ & $211[13]$ & $2.8 \times 10^{17}$ & $5.9 \times 10^{16}$ & $1.2 \times 10^{17}$ & $2.3 \times 10^{15}$ & $1.3 \times 10^{13}$ \\
\hline $\mathrm{G} 75.78^{32}$ & $\mathrm{HC}$ & $113[7]$ & $1.1 \times 10^{17}$ & $1.8 \times 10^{15}$ & $2.3 \times 10^{16}$ & $8.6 \times 10^{14}$ & $2.1 \times 10^{13}$ \\
\hline NGC 6334 IRS1 32 & $\mathrm{HC}$ & $178[10]$ & $9.7 \times 10^{17}$ & $2.9 \times 10^{16}$ & $5.8 \times 10^{17}$ & $5.2 \times 10^{15}$ & $1.2 \times 10^{14}$ \\
\hline NGC 7538 IRS 132 & $\mathrm{HC}$ & $156[10]$ & $1.2 \times 10^{17}$ & $8.2 \times 10^{15}$ & $1.6 \times 10^{16}$ & $8.4 \times 10^{14}$ & $2.8 \times 10^{13}$ \\
\hline $\mathrm{W} 3(\mathrm{H} 2 \mathrm{O})^{3}$ & $\mathrm{HC}$ & $139[8]$ & $1.0 \times 10^{18}$ & $7.0 \times 10^{15}$ & $1.5 \times 10^{17}$ & $1.5 \times 10^{15}$ & $3.5 \times 10^{13}$ \\
\hline $\mathrm{W} 33 \mathrm{~A}^{32}$ & $\mathrm{HC}$ & $259[16]$ & $2.0 \times 10^{17}$ & $2.7 \times 10^{16}$ & $2.7 \times 10^{16}$ & $1.3 \times 10^{15}$ & $3.0 \times 10^{13}$ \\
\hline NGC7538 IRS9 ${ }^{34}$ & MYSO & $25[2]$ & $9[1] \times 10^{14}$ & $1[0.3] \times 10^{13}$ & $5[2] \times 10^{13}$ & $1.2[0.3] \times 10^{15}$ & $3.1[0.4] \times 10^{13}$ \\
\hline W3 IRS5 ${ }^{34}$ & MYSO & $64[6]$ & $3.2[0.4] \times 10^{14}$ & $4[1] \times 10^{12}$ & $1.5[0.6] \times 10^{13}$ & $7[2] \times 10^{14}$ & $<1.1 \times 10^{13}$ \\
\hline AFGL 49 & MYSO & $25[2]$ & $2.4[0.4] \times 10^{14}$ & $6[2] \times 10^{12}$ & $8[3] \times 10^{13}$ & $4[2] \times 10^{14}$ & $<1.3 \times 10^{13}$ \\
\hline B1-b 10,35 & $\mathrm{CC}$ & $10[5]$ & $4 \times 10^{14}$ & - & $3 \times 10^{12}$ & - & $5[1] \times 10^{12}$ \\
\hline SMM4-W 11 & LYSO & $11[1]$ & $2.2[0.7] \times 10^{15}$ & - & $2.4 \times 10^{13}$ & - & $1.3 \times 10^{14}$ \\
\hline SMM1 ${ }^{11}$ & LYSO & $16[1]$ & $2.5[0.3] \times 10^{14}$ & - & $1.3 \times 10^{13}$ & - & $1.7 \times 10^{13}$ \\
\hline SMM $4{ }^{11}$ & LYSO & $13[1]$ & $1.1[0.1] \times 10^{15}$ & - & $8.4 \times 10^{12}$ & - & $2.3 \times 10^{13}$ \\
\hline $\mathrm{L} 1157^{7}$ & outflow & $12[2]$ & $1.5 \times 10^{15}$ & $1[0.5] \times 10^{12}$ & - & - & - \\
\hline NGC1333 IRAS 4a $2,5,36$ & LYSO & $24[2]$ & $5.1 \times 10^{14}$ & - & $1.1 \times 10^{14}$ & - & - \\
\hline NGC1333 IRAS $4 \mathrm{~b} 2,5,36$ & LYSO & $34[4]$ & $3.5 \times 10^{14}$ & $9[1] \times 10^{11}$ & $<6.7 \times 10^{13}$ & - & $3.5 \times 10^{13}$ \\
\hline NGC1333 IRAS 2a 5,36 & LYSO & $101[16]$ & $3.4 \times 10^{14}$ & $4[1] \times 10^{12}$ & $<2 \times 10^{14}$ & - & $3.5 \times 10^{13}$ \\
\hline IRAS16293 2-4 & LYSO & 85 & $8.8 \times 10^{14}$ & - & $1.8] \times 10^{14}$ & - & $3.5 \times 10^{13}$ \\
\hline IRAS16293 A 37,38 & LYSO HC & 100 & $1.1 \times 10^{18}$ & $3 \times 10^{15}$ & - & - & $<1 \times 10^{14}$ \\
\hline IRAS16293 B 37,38 & LYSO HC & 100 & $5 \times 10^{17}$ & $5 \times 10^{15}$ & - & - & $1.5 \times 10^{15}$ \\
\hline Sgr B2(N) 39 & GC halo & 45 & $1 \times 10^{16}$ & - & - & - & $4.0[0.6] \times 10^{14}$ \\
\hline Sgr B2(N) 39 & GC HC & 238 & $5 \times 10^{18}$ & $6[2] \times 10^{17}$ & $8[0.8] \times 10^{15}$ & - & - \\
\hline Sgr B2(M) ${ }^{39}$ & GC halo & 40 & $1 \times 10^{16}$ & - & - & - & $2.7[0.5] \times 10^{14}$ \\
\hline Sgr B2(M) ${ }^{39}$ & $\mathrm{GC} \mathrm{HC}$ & 150 & $8 \times 10^{18}$ & $3[2] \times 10^{17}$ & - & - & - \\
\hline G19.61-0.23 40 & $\mathrm{HC}$ & $151[6]$ & $5.2[6] \times 10^{17}$ & $4.1[0.8] \times 10^{16}$ & $1.4[0.1] \times 10^{16}$ & - & $9.7[0.8] \times 10^{15}$ \\
\hline $\mathrm{G} 34.26+0.15 \mathrm{NE}^{41,42}$ & $\mathrm{HC}$ & 150 & $3.4 \times 10^{17}$ & $1.3] \times 10^{16}$ & $5.7 \times 10^{16}$ & - & - \\
\hline $\mathrm{G} 34.26+0.15 \mathrm{SE}^{41}$ & $\mathrm{HC}$ & 150 & $2.6 \times 10^{17}$ & - & $3.4 \times 10^{16}$ & - & - \\
\hline IRDC316.76-1 43 & IRDC & 38 & $4.6[1.1] \times 10^{14}$ & - & - & $6.2 \times 10^{14}$ & - \\
\hline IRDC $316.76-243$ & IRDC & 53 & $2.5 \times 10^{13}$ & - & - & $3[2] \times 10^{14}$ & - \\
\hline IRDC317.71-2 43 & IRDC & 12 & $1.6 \times 10^{14}$ & - & - & $612 \times 10^{14}$ & - \\
\hline IRDC019.30-1 43 & IRDC & 25 & $1.5[0.1] \times 10^{15}$ & - & $<7.6 \times 10^{13}$ & $1.1[0.2] \times 10^{14}$ & $1.5[1.0] \times 10^{14}$ \\
\hline IRDC028.34-6 ${ }^{43}$ & IRDC & 43 & $1.2[0.1] \times 10^{15}$ & - & $<1.6 \times 10^{14}$ & $2.8[0.2] \times 10^{14}$ & $9.1[0.8] \times 10^{13}$ \\
\hline IRDC011.11-4 43 & IRDC & 28 & $2.3[0.8] \times 10^{14}$ & - & - & $1.9[0.4] \times 10^{14}$ & $7[5] \times 10^{14}$ \\
\hline IRDC028.34-3 ${ }^{43}$ & IRDC & 32 & $4.3[1.7] \times 10^{15}$ & - & $<9.9 \times 10^{13}$ & $9.7[1.5] \times 10^{13}$ & $1.7[1.1] \times 10^{14}$ \\
\hline NGC7129 FIRS2 44 & IMC & 80 & $2 \times 10^{14}$ & $3.6 \times 10^{12}$ & - & - & - \\
\hline
\end{tabular}

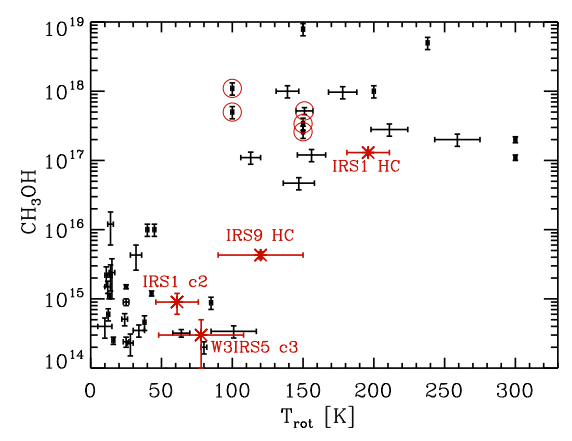

Fig. $7 \mathrm{CH}_{3} \mathrm{OH}$ column density vs excitation temperature for the sample in Table 4 (black, and black with red circles for resolved observations) and our spatially resolved sample in Table 3 (red stars). Together these two parameters define two clearly distinguishable groups in the literature sample: cold $(\mathrm{T}<100 \mathrm{~K}) \mathrm{COM}$ sources and hot cores. In contrast, our small spatially resolved sample suggests a more continuous distribution.

12 | Faraday Discuss., [year], [vol], 1-19

This journal is $\odot$ The Royal Society of Chemistry [year] 
as a whole, $\mathrm{CH}_{3} \mathrm{CN} / \mathrm{CH}_{3} \mathrm{OH}$ correlates with temperature. This correlation is significant at the $99.9 \%$ level, based on the computation of the Spearman's rank correlation coefficient. No correlation is seen in our spatially resolved sample, but this may be a question of sample size, since the scatter around the general trend is considerable. $\mathrm{CH}_{3} \mathrm{OCH}_{3}$ shows no sign of correlation. Both $\mathrm{CH}_{3} \mathrm{CCH} / \mathrm{CH}_{3} \mathrm{OH}$ and $\mathrm{CH}_{3} \mathrm{CHO} / \mathrm{CH}_{3} \mathrm{OH}$ appear to depend inversely on the temperature when comparing the $\mathrm{T}<100 \mathrm{~K}$ and $\mathrm{T}>100 \mathrm{~K}$ sources, i.e. these two ratios seem to distinguish between the hot core and colder sources quite well. Furthermore, the $\mathrm{CH}_{3} \mathrm{CCH} / \mathrm{CH}_{3} \mathrm{OH}$ ratio increases with temperature between 10 and $50 \mathrm{~K}$, indicative of formation at these temperatures.

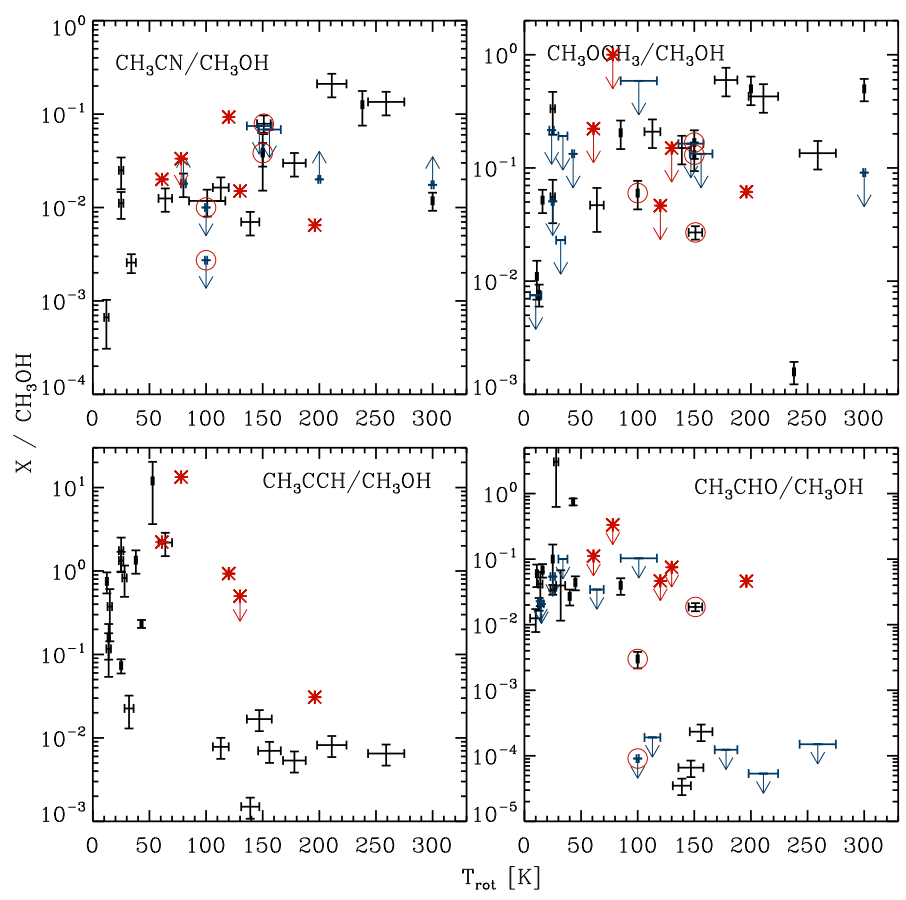

Fig. 8 The column density ratios of $\mathrm{CH}_{3} \mathrm{CN}, \mathrm{CH}_{3} \mathrm{OCH}_{3}, \mathrm{CH}_{3} \mathrm{CCH}, \mathrm{CH}_{3} \mathrm{CHO}$, and $\mathrm{CH}_{3} \mathrm{OH}$ plotted as a function of excitation temperatures. Sources from the literature are in black, and our MYSOs in red (error bars are not shown here for sake of visibility they are plotted in Fig. 9, however, for the same molecular ratios). Spatially resolved observations from the literature are marked with a circle.

We specifically checked whether there is any difference between previous unresolved and spatially resolved observations, and find none for $\mathrm{CH}_{3} \mathrm{CN}$ or $\mathrm{CH}_{3} \mathrm{OCH}_{3}$, except that NGC 7538 IRS1 has unusually little $\mathrm{CH}_{3} \mathrm{CN}$ compared to other sources with similar excitation temperatures. $\mathrm{CH}_{3} \mathrm{CN}$ may be underestimated in this source, however, since there are clear line asymmetries that indicate that some self absorption is present. For $\mathrm{CH}_{3} \mathrm{CHO} / \mathrm{CH}_{3} \mathrm{OH}$ the spatially resolved hot cores appear to have a higher $\mathrm{CH}_{3} \mathrm{CHO} / \mathrm{CH}_{3} \mathrm{OH}$ ratio compared to those inferred from single-dish observations, suggestive of there being two $\mathrm{CH}_{3} \mathrm{CHO}$ distributions and formation pathways, a cold one that dominates single dish ob- 
servations, and a warm component that is picked up with spatially resolved observations. Our MYSO core measurements also indicate a more continuous fall-off with temperature of $\mathrm{CH}_{3} \mathrm{CCH} / \mathrm{CH}_{3} \mathrm{OH}$ across the $100 \mathrm{~K}$ line, indicative of a less sharp distinction between sources colder and warmer than $100 \mathrm{~K}$, similar to what was seen for $\mathrm{CH}_{3} \mathrm{OH}$ column densities in Fig. 7.

Figure 7 suggests that the total $\mathrm{CH}_{3} \mathrm{OH}$ column density is an equally good measure of hot core activity as excitation temperature, and we therefore also investigated its relationship with different $\mathrm{COM} / \mathrm{CH}_{3} \mathrm{OH}$ ratios. Maybe surprisingly, Figure 9 shows that $\mathrm{CH}_{3} \mathrm{CN} / \mathrm{CH}_{3} \mathrm{OH}$ is not correlated with $\mathrm{CH}_{3} \mathrm{OH}$ column density. Nor is $\mathrm{CH}_{3} \mathrm{OCH}_{3} / \mathrm{CH}_{3} \mathrm{OH}$. $\mathrm{CH}_{3} \mathrm{CCH} / \mathrm{CH}_{3} \mathrm{OH}$ is very strongly inversely correlated with the $\mathrm{CH}_{3} \mathrm{OH}$ column, but this is related to the relatively small spread in $\mathrm{CH}_{3} \mathrm{CCH}$ column densities across the sample, as reported above. $\mathrm{CH}_{3} \mathrm{CHO}$ presents a shallow decrease with $\mathrm{CH}_{3} \mathrm{OH}$ column up to $10^{16} \mathrm{~cm}^{-2}$. Beyond $10^{16} \mathrm{~cm}^{-2} \mathrm{CH}_{3} \mathrm{CHO} / \mathrm{CH}_{3} \mathrm{OH}$ abundances vary by three orders of magnitude, which supports the analysis of the temperature trend in Fig. 8, i.e. $\mathrm{CH}_{3} \mathrm{CHO}$ is common at low temperatures, but in some sources it is also present in excess in hot cores.

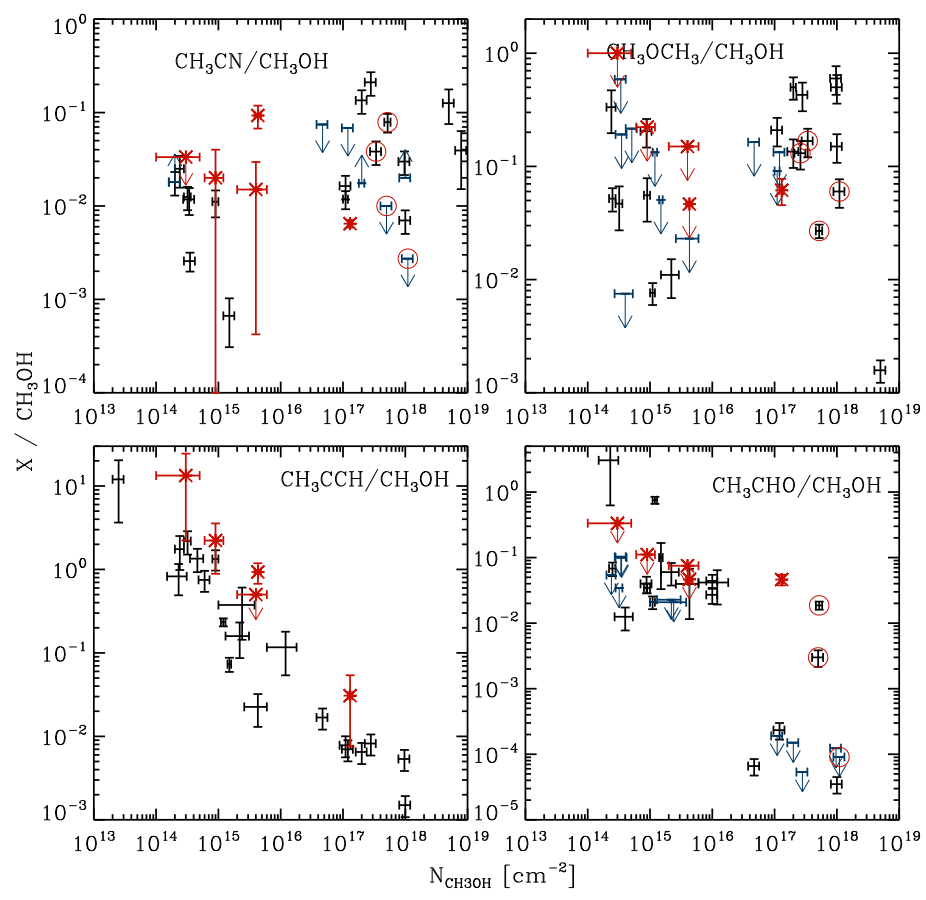

Fig. 9 The column density ratios of $\mathrm{CH}_{3} \mathrm{CN}, \mathrm{CH}_{3} \mathrm{OCH}_{3}, \mathrm{CH}_{3} \mathrm{CCH}, \mathrm{CH}_{3} \mathrm{CHO}$, and $\mathrm{CH}_{3} \mathrm{OH}$ plotted as a function of $\mathrm{CH}_{3} \mathrm{OH}$ column densities. Sources from the literature are in black, and our MYSOs in red. Spatially resolved observations from the literature are marked with a circle.

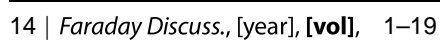

This journal is $\odot$ The Royal Society of Chemistry [year] 


\section{Discussion}

The observed dependencies (or lack thereof) of complex organic molecule abundances on temperature can be used to put empirical constraints on the COM chemistry. Most complex molecules have many potential formation pathways with different expected dependencies on temperature. This has been explored extensively in chemical models of hot cores. For example, $\mathrm{CH}_{3} \mathrm{CN}$ can form on grains via $\mathrm{CH}_{3}+\mathrm{CN}$ at $\sim 30 \mathrm{~K}$. It can also form from $\mathrm{HCN}$ in the gas-phase, when $\mathrm{HCN}$ evaporates at $\sim 40 \mathrm{~K}$, through $\mathrm{CH}_{3}^{+}+\mathrm{HCN}$ association followed by a recombination reaction ${ }^{14}$. This gas-phase $\mathrm{CH}_{3} \mathrm{CN}$ re-accretes onto the grains, and can then thermally evaporate around $90 \mathrm{~K}$.

$\mathrm{COM}$ abundances are often compared with $\mathrm{CH}_{3} \mathrm{OH}$ abundances, because of its ubiquity and its proposed early formation at $10 \mathrm{~K}$ in ices. The presence of $\mathrm{CH}_{3} \mathrm{OH}$ in the gas phase implies efficient desorption at all temperatures, but clearly a much more efficient desorption pathway is activated at $100 \mathrm{~K}$. This is consistent with theoretical expectation of low levels of non-thermal desorption at all temperatures (resulting in the release of a fraction of a $\%$ of the ice into the gas phase) and rapid thermal desorption above $100 \mathrm{~K}$. The scatter in $\mathrm{CH}_{3} \mathrm{OH}$ abundances below $100 \mathrm{~K}$ is probably due to a combination of different initial $\mathrm{CH}_{3} \mathrm{OH}$ ice abundances and different non-thermal desorption efficiencies. Above $100 \mathrm{~K}$, different initial $\mathrm{CH}_{3} \mathrm{OH}$ ice abundances and destruction pathways are likely causes of the observed order of magnitude column density variation. Most COMs are expected to desorb thermally and non-thermally similarly to $\mathrm{CH}_{3} \mathrm{OH}$, though this has yet to be quantified. Therefore differences in $\mathrm{COM} / \mathrm{CH}_{3} \mathrm{OH}$ abundance ratios across MYSOs and samples of sources should be mainly due to differences in the chemical evolution or initial conditions.

One of the clearest trends in this study is the increase of $\mathrm{CH}_{3} \mathrm{CN}$ column density, and further the increase in $\mathrm{CH}_{3} \mathrm{CN} / \mathrm{CH}_{3} \mathrm{OH}$ with temperature. This increase appears to be smooth, and cannot be due to a sudden onset of $\mathrm{CH}_{3} \mathrm{CN}$ thermal evaporation at a single temperature. Rather it implies an increasingly efficient $\mathrm{CH}_{3} \mathrm{CN}$ formation in the ice or gas as the temperature increases between 10 and $100 \mathrm{~K}$, and potentially the onset of a second hot gas-phase chemistry above $100 \mathrm{~K}$ to explain the relative increase between 100 and $200 \mathrm{~K}$ in $\mathrm{CH}_{3} \mathrm{CN} / \mathrm{CH}_{3} \mathrm{OH}$ in this temperature range. The continuous increase in $\mathrm{CH}_{3} \mathrm{CN} / \mathrm{CH}_{3} \mathrm{OH}$ with temperature means that with ALMA, this ratio could become a powerful diagnostic of the evolutionary stage of MYSOs.

$\mathrm{CH}_{3} \mathrm{OCH}_{3}$ has an almost constant ratio of $14 \%$ w.r.t $\mathrm{CH}_{3} \mathrm{OH}$ (lower and upper quartiles are 5 and $33 \%$ respectively), indicative of co-formation or a constant conversion factor of $\mathrm{CH}_{3} \mathrm{OH}$ into $\mathrm{CH}_{3} \mathrm{OCH}_{3}$ at all temperatures. This is most readily explained if $\mathrm{CH}_{3} \mathrm{OCH}_{3}$ forms from $\mathrm{CH}_{3} \mathrm{OH}$ ice dissociation chemistry and then co-desorbs both thermally and non-thermally. $\mathrm{CH}_{3} \mathrm{OCH}_{3} / \mathrm{CH}_{3} \mathrm{OH}$ ratios may thus serve as a signpost of the overall efficiency of conversion of simple ices into more complex ones.

$\mathrm{CH}_{3} \mathrm{CCH} / \mathrm{CH}_{3} \mathrm{OH}$ displays two clear trends. First, the $\mathrm{CH}_{3} \mathrm{CCH}$ column densities vary significantly less than any other complex molecule, which results in a steep inverse relationship between $\mathrm{CH}_{3} \mathrm{CCH} / \mathrm{CH}_{3} \mathrm{OH}$ and $\mathrm{CH}_{3} \mathrm{OH}$ column. This is indicative of early $\mathrm{CH}_{3} \mathrm{CCH}$ formation and no hot core chemistry contribution to its abundance. Second, the $\mathrm{CH}_{3} \mathrm{CCH} / \mathrm{CH}_{3} \mathrm{OH}$ ratio peaks around $50 \mathrm{~K}$. Thus at 
low temperatures $\mathrm{CH}_{3} \mathrm{CCH}$ production is increasing compared to $\mathrm{CH}_{3} \mathrm{OH}$ nonthermal desorption, indicative of either a thermal desorption pathway below $50 \mathrm{~K}$, or cold gas-phase chemistry, or a combination of the two, e.g. thermal evaporation of $\mathrm{CH}_{4}$ around $25 \mathrm{~K}$ followed by gas-phase formation of $\mathrm{CH}_{3} \mathrm{CCH}$. In either case $\mathrm{CH}_{3} \mathrm{CCH} / \mathrm{CH}_{3} \mathrm{OH}$ has the potential to constrain the relative importance of hot core and non-hot core driven complex chemistry in unresolved observations encompassing both envelopes and protostellar cores.

The $\mathrm{CH}_{3} \mathrm{CHO} / \mathrm{CH}_{3} \mathrm{OH}$ abundances also display a negative dependence on temperature, but the trend is complicated by a few outliers that suggest that in some sources there exists a high-temperature formation pathway of $\mathrm{CH}_{3} \mathrm{CHO}$. The fact that these outliers are all spatially resolved observations is notable, and as more spatially resolved observations appear we may find that an increase in the $\mathrm{CH}_{3} \mathrm{CHO}$ abundance is a common feature of hot core chemistry. This second formation pathway could be either due to warm ice chemistry followed by thermal desorption with $\mathrm{CH}_{3} \mathrm{OH}$, or to hot gas-phase chemistry. Quantifying the $\mathrm{CH}_{3} \mathrm{CHO}$ abundances at all scales will be important to understand differences between cold and warm COM formation pathways and how these pathways together shape the final complex organic composition.

This set of empirical constraints can also be used to directly evaluate models of the complex chemistry during star formation including, especially with regard to the predicted onset of hot core activity, the temperature dependence of different COM ratios, and the sensitivity of different ratios to environmental factors other than the current temperature.

Regardless of warm-up timescale, recent models predict that $\mathrm{CH}_{3} \mathrm{OH}$ and most other COMs should thermally evaporate at $\sim 100 \mathrm{~K}$, resulting in rapid increases in $\mathrm{CH}_{3} \mathrm{OH}$ and $\mathrm{COM}$ column densities, often by many orders of magnitude. This compares well with the bimodal distribution of $\mathrm{CH}_{3} \mathrm{OH}$ column densities in our sample, defined by a sharp transition at $100 \mathrm{~K}$ from $\mathrm{CH}_{3} \mathrm{OH}$ columns of $\sim 10^{15} \mathrm{~cm}^{-2}$ to $\sim 10^{17} \mathrm{~cm}^{-2}$. This confirms (1) model predictions of a very sharp transition between $\mathrm{CH}_{3} \mathrm{OH}$ ice and gas dominated regimes, i.e. a well-defined snow line, and (2) that the current estimates of the temperature location of this snow line are approximately right.

To evaluate the agreement between models and observations for specific COM abundances, Figure 10 shows model predictions for $\mathrm{COM} / \mathrm{CH}_{3} \mathrm{OH}$ ratios, using a recent model that includes a detailed ice surface and bulk chemistry treatment, a suite of desorption mechanisms, and a full gas-phase chemistry network, and assuming a medium warm-up time scale (i.e. $2 \times 10^{5}$ years for warm-up to $200 \mathrm{~K})^{14}$. For $\mathrm{CH}_{3} \mathrm{CN} / \mathrm{CH}_{3} \mathrm{OH}$, the theoretical abundance ratio increase of two orders of magnitude with temperature up to $100 \mathrm{~K}$ agrees well with observations. The model drop-off at $100 \mathrm{~K}$ is not seen in observations, however. $\mathrm{CH}_{3} \mathrm{OCH}_{3} / \mathrm{CH}_{3} \mathrm{OH}$ displays a more complex dependence on temperature, consistent with the lack of a clear temperature dependence in the observational sample. $\mathrm{CH}_{3} \mathrm{CCH} / \mathrm{CH}_{3} \mathrm{OH}$ is predicted to increase by eight orders of magnitude between 15 and $30 \mathrm{~K}$, followed by a slow drop-off at 30-100 K, and a steep decline at $100 \mathrm{~K}$. Qualitatively, observations tell a similar story, with an increasing ratio between 10 and $50 \mathrm{~K}$, followed by a flattening or decline, and then a steep drop around $100 \mathrm{~K}$. Quantitatively, there is little agreement, however, and the current network seems to underproduce $\mathrm{CH}_{3} \mathrm{CCH}$ below $20 \mathrm{~K}$, and over-produce it at 
25-40 K. Finally, the predicted flat $\mathrm{CH}_{3} \mathrm{CHO} / \mathrm{CH}_{3} \mathrm{OH}$ trend followed by a steep drop at $100 \mathrm{~K}$ is in excellent agreement with most observations, but does not account for the hot $\mathrm{CH}_{3} \mathrm{CHO}$ component seen in some sources. In summary, current state-of-the-art astrochemical models capture many of the observed trends in this data set, but there seem to be some hot formation pathways missing.

Finally, the scatter in $\mathrm{COM} / \mathrm{CH}_{3} \mathrm{OH}$ temperature relations should probe the sensitivity of the COM chemistry to environmental conditions other than temperature. For example, observationally $\mathrm{CH}_{3} \mathrm{CCH}$ columns are remarkably constant, and therefore models predicting a strong dependence on the environment for this molecule would be problematic. In contrast $\mathrm{CH}_{3} \mathrm{CN} / \mathrm{CH}_{3} \mathrm{OH}$ varies by more than an order of magnitude in each temperature bin, and model predictions indicating that this ratio should be sensitive to e.g. collapse timescale are perfectly consistent with this observed scatter ${ }^{13}$.

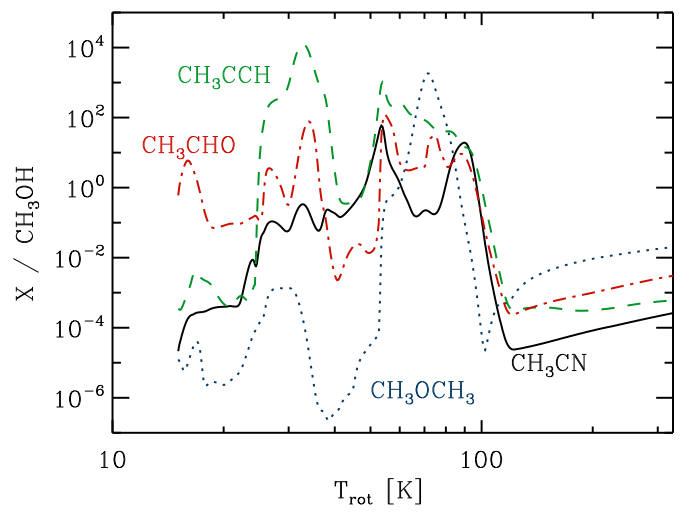

Fig. 10 Model predictions of the $\mathrm{COM}$ to $\mathrm{CH}_{3} \mathrm{OH}$ ratios as a function of temperature during massive star formation, adapted from Garrod (2013) ${ }^{14}$

\section{Conclusions}

Based on the combined analysis of the spatial distribution of COMs toward three MYSOs and, mostly spatially unresolved, COM observations in the literature, we find that:

1. MYSOs display a systematic chemical differentiation including spatially separated $\mathrm{CH}_{3} \mathrm{CN}, \mathrm{CH}_{3} \mathrm{OH}$ and $\mathrm{CH}_{3} \mathrm{CCH}$ emission peaks, where the $\mathrm{CH}_{3} \mathrm{CN}$ and $\mathrm{CH}_{3} \mathrm{OH}$ peaks trace hot material and $\mathrm{CH}_{3} \mathrm{CCH}$ colder material. Toward the MYSO W3 IRS5 there are at least four distinguishable chemical peaks: $\mathrm{SO}_{2}+\mathrm{CH}_{3} \mathrm{SH}, \mathrm{CH}_{3} \mathrm{CN}+\mathrm{HNCO}, \mathrm{CH}_{3} \mathrm{OH}, \mathrm{HC}_{3} \mathrm{~N}+\mathrm{H}_{2} \mathrm{CS}+\mathrm{CH}_{3} \mathrm{CCH}$.

2. $\mathrm{CH}_{3} \mathrm{OH}$ column densities are observed to strongly depend on whether the derived excitation temperatures are above or below $100 \mathrm{~K}$, but do not vary significantly with temperature within these two temperature bins.

3. The $\mathrm{CH}_{3} \mathrm{CCH} / \mathrm{CH}_{3} \mathrm{OH}$ ratio is correlated with temperature at $10-50 \mathrm{~K}$ and anti-correlated with temperature above $50 \mathrm{~K}$. The $\mathrm{CH}_{3} \mathrm{CN} / \mathrm{CH}_{3} \mathrm{OH}$ ratio increases with temperature, and, with a few notable exceptions, $\mathrm{CH}_{3} \mathrm{CHO} / \mathrm{CH}_{3} \mathrm{OH}$ decreases sharply around $100 \mathrm{~K}$. These observations together suggest that 
$\mathrm{CH}_{3} \mathrm{CCH}$ only forms at low temperatures, that $\mathrm{CH}_{3} \mathrm{CHO}$ forms efficiently at low temperatures, but has a second high-temperature formation pathway that sometimes becomes activated, and that the relative formation efficiency of $\mathrm{CH}_{3} \mathrm{CN}$ with respect to $\mathrm{CH}_{3} \mathrm{OH}$ increases with temperature. This is generally consistent with model predictions.

4. The formation of some COMs is already efficient at low temperatures, but the COM composition strongly depends on the source temperature, and the combination of $\mathrm{CH}_{3} \mathrm{CN}, \mathrm{CH}_{3} \mathrm{OH}$ and $\mathrm{CH}_{3} \mathrm{CCH}$ observations may therefore be used to define the evolutionary stage of an object in terms of its COM chemistry.

In general, spatially resolved observations are key to deconvolve the contributions from cores at different chemical stages, which will typically be confused by single-dish observations, and thus constrain how the complex chemistry depends on its environment and the evolutionary stage of the core. This approach becomes particularly powerful when multiple emission lines of each molecule are imaged, enabling constraints on both the chemical and temperature structures of an MYSO region. Temperature is not the only regulator of chemistry, however, and to explain e.g. differences between $\mathrm{N}$ and $\mathrm{S}$ cores requires either differences in initial chemical conditions (ice compositions) or the dominance of energy sources other than passive heating from the central star.

This opens leads to the question of the relative importance of nature and nurture for COM chemistry, and how to observationally test it. Can we for example identify ratios that exclusively trace the initial conditions, i.e. ratios of COMs that evolve similarly with temperature, but depend strongly on the initial ice composition or collapse history? Addressing this question observationally requires spatially resolved observations that can follow the chemistry from envelope to core. In general high-spatial resolution is key to unravel the complex chemical structures of MYSOs, but it is still an open question how MYSO spectral data cubes are best mined for information, and how this information is best displayed and quantified.

\section{Acknowledgements}

The authors are grateful to Robin T. Garrod for sharing his complex chemistry model results.

\section{References}

1 G. A. Blake, E. C. Sutton, C. R. Masson and T. G. Phillips, ApJ, 1987, 315, 621-645.

2 E. Herbst and E. F. van Dishoeck, ARA\&A, 2009, 47, 427-480.

3 E. F. van Dishoeck, G. A. Blake, D. J. Jansen and T. D. Groesbeck, ApJ, 1995, 447, 760.

4 S. Cazaux, A. G. G. M. Tielens, C. Ceccarelli, A. Castets, V. Wakelam, E. Caux, B. Parise and D. Teyssier, ApJL, 2003, 593, L51-L55.

5 S. Bottinelli, C. Ceccarelli, J. P. Williams and B. Lefloch, A\&A, 2007, 463, 601-610.

6 K. I. Öberg, N. van der Marel, L. E. Kristensen and E. F. van Dishoeck, ApJ, 2011, 740, 14.

7 H. G. Arce, J. Santiago-García, J. K. Jørgensen, M. Tafalla and R. Bachiller, ApJL, 2008, 681, L21-L24.

8 K. I. Öberg, S. Bottinelli, J. K. Jørgensen and E. F. van Dishoeck, ApJ, 2010, 716, 825-834.

18 | Faraday Discuss., [year], [vol], 1-19

This journal is $\odot$ The Royal Society of Chemistry [year] 
9 A. Bacmann, V. Taquet, A. Faure, C. Kahane and C. Ceccarelli, A\&A, 2012, 541, L12.

10 J. Cernicharo, N. Marcelino, E. Roueff, M. Gerin, A. Jiménez-Escobar and G. M. Muñoz Caro, ApJL, 2012, 759, L43.

11 K. I. Öberg, A. C. A. Boogert, K. M. Pontoppidan, S. van den Broek, E. F. van Dishoeck, S. Bottinelli, G. A. Blake and N. J. Evans, II, ApJ, 2011, 740, 109.

12 K. I. Öberg, M. D. Boamah, E. C. Fayolle, R. T. Garrod, C. J. Cyganowski and F. van der Tak, ApJ, 2013, 771, 95.

13 R. T. Garrod, S. L. W. Weaver and E. Herbst, ApJ, 2008, 682, 283-302.

14 R. T. Garrod, ApJ, 2013, 765, 60.

15 A. G. G. M. Tielens and W. Hagen, $A \& A, 1982,114,245-260$.

16 R. T. Garrod and T. Pauly, ApJ, 2011, 735, 15.

17 S. B. Charnley, A. G. G. M. Tielens and T. J. Millar, ApJL, 1992, 399, L71-L74.

18 K. I. Öberg, R. T. Garrod, E. F. van Dishoeck and H. Linnartz, A\&A, 2009, 504, 891-913.

19 F. F. S. van der Tak, E. F. van Dishoeck and P. Caselli, $A \& A, 2000,361,327-339$.

20 F. F. S. van der Tak, P. G. Tuthill and W. C. Danchi, $A \& A, 2005,431,993-1005$.

21 S. T. Megeath, T. L. Wilson and M. R. Corbin, ApJL, 2005, 622, L141-L144.

22 J. A. Rodón, H. Beuther, S. T. Megeath and F. F. S. van der Tak, A\&A, 2008, 490, 213-222.

23 L. Chavarría, F. Herpin, T. Jacq, J. Braine, S. Bontemps, A. Baudry, M. Marseille, F. van der Tak, B. Pietropaoli, F. Wyrowski, R. Shipman, W. Frieswijk, E. F. van Dishoeck, J. Cernicharo, R. Bachiller, M. Benedettini, A. O. Benz, E. Bergin, P. Bjerkeli, G. A. Blake, S. Bruderer, P. Caselli, C. Codella, F. Daniel, A. M. di Giorgio, C. Dominik, S. D. Doty, P. Encrenaz, M. Fich, A. Fuente, T. Giannini, J. R. Goicoechea, T. de Graauw, P. Hartogh, F. Helmich, G. J. Herczeg, M. R. Hogerheijde, D. Johnstone, J. K. Jørgensen, L. E. Kristensen, B. Larsson, D. Lis, R. Liseau, C. McCoey, G. Melnick, B. Nisini, M. Olberg, B. Parise, J. C. Pearson, R. Plume, C. Risacher, J. Santiago-García, P. Saraceno, J. Stutzki, R. Szczerba, M. Tafalla, A. Tielens, T. A. van Kempen, R. Visser, S. F. Wampfler, J. Willem and U. A. Yıldız, A\&A, 2010, 521, L37.

24 K.-S. Wang, T. L. Bourke, M. R. Hogerheijde, F. F. S. van der Tak, A. O. Benz, S. T. Megeath and T. L. Wilson, $A \& A, 2013, \mathbf{5 5 8}$, A69.

25 F. P. Helmich, D. J. Jansen, T. de Graauw, T. D. Groesbeck and E. F. van Dishoeck, $A \& A, 1994$, 283, 626-634.

26 J. P. McMullin, B. Waters, D. Schiebel, W. Young and K. Golap, Astronomical Data Analysis Software and Systems XVI, 2007, p. 127.

27 D. J. Wilner and W. J. Welch, ApJ, 1994, 427, 898-913.

28 F. F. S. van der Tak, E. F. van Dishoeck, N. J. Evans, II and G. A. Blake, ApJ, 2000, 537, 283-303.

29 H. M. Pickett, R. L. Poynter, E. A. Cohen, M. L. Delitsky, J. C. Pearson and H. S. P. Müller, Journal of Quantitative Spectroscopy and Radiative Transfer, 1998, 60, 883-890.

30 H. S. P. Müller, S. Thorwirth, D. A. Roth and G. Winnewisser, A\&A, 2001, 370, L49-L52.

31 P. F. Goldsmith and W. D. Langer, ApJ, 1999, 517, 209-225.

32 S. E. Bisschop, J. K. Jørgensen, E. F. van Dishoeck and E. B. M. de Wachter, $A \& A, 2007$, 465, 913-929.

33 K. Isokoski, S. Bottinelli and E. F. van Dishoeck, $A \& A, 2013, \mathbf{5 5 4}$, A100.

34 E. C. Fayolle, K. I. Öberg, R. Garrod, S. Bisschop and E. van Dishoeck, submitted to A\&A, 2014.

35 K. I. Öberg, S. Bottinelli and E. F. van Dishoeck, A\&A, 2009, 494, L13-L16.

36 S. Maret, C. Ceccarelli, A. G. G. M. Tielens, E. Caux, B. Lefloch, A. Faure, A. Castets and D. R. Flower, $A \& A, 2005,442,527-538$.

37 Y. Kuan, H. Huang, S. B. Charnley, N. Hirano, S. Takakuwa, D. J. Wilner, S. Liu, N. Ohashi, T. L. Bourke, C. Qi and Q. Zhang, ApJL, 2004, 616, L27-L30.

38 S. E. Bisschop, J. K. Jørgensen, T. L. Bourke, S. Bottinelli and E. F. van Dishoeck, A\&A, 2008, 488, 959-968.

39 A. Nummelin, P. Bergman, Å. Hjalmarson, P. Friberg, W. M. Irvine, T. J. Millar, M. Ohishi and S. Saito, ApJs, 2000, 128, 213-243.

40 S.-L. Qin, Y. Wu, M. Huang, G. Zhao, D. Li, J.-J. Wang and S. Chen, ApJ, 2010, 711, 399-416.

41 B. Mookerjea, E. Casper, L. G. Mundy and L. W. Looney, ApJ, 2007, 659, 447-458.

42 S. Watt and L. G. Mundy, ApJS, 1999, 125, 143-160.

43 T. Vasyunina, A. I. Vasyunin, E. Herbst, H. Linz, M. Voronkov, T. Britton, I. Zinchenko and F. Schuller, ArXiv e-prints, 2013.

44 A. Fuente, R. Neri and P. Caselli, $A \& A$, 2005, 444, 481-493. 